\title{
Tooth whitening efficacy of self-directed whitening agents vs. 10\% carbamide peroxide: A randomized clinical study
}

\author{
Antoniadou $\mathrm{M}^{1 *}$, Koniaris Antonios ${ }^{1}$, Kakaboura Afrodite ${ }^{1}$ and Margaritis Vasileios ${ }^{2}$ \\ ${ }^{1}$ Department of Operative Dentistry, Dental School of Athens, Greece \\ ${ }^{2}$ College of Health Sciences, Walden University, USA
}

\begin{abstract}
Objective: This randomized, controlled, single-blind, four parallel group clinical study evaluated the potential for tooth colour whitening by self-directed whitening agents - two whitening dentifrices and a peroxide barrier-free varnish - in comparison to a $10 \%$ carbamide peroxide agent (CP) as positive control for a period up to 90 days, in young adults.

Materials and methods: The colour of 5 anterior teeth (\# 12, 21, 23, 33, 41) was measured in each of 96 Caucasian people aged between 20-30 years, studying or working at the Dental School of Athens, Greece. Participants were randomized into four-parallel, controlled, single-blind groups: Group A and B used two different whitening dentifrices, accordingly; $\mathrm{C}$ a peroxide barrier-free varnish and, D 10\% CP in custom-made trays. Colour assessment was performed by the SpectroShade device (MHT Optic Research) in L*, a*, $\mathrm{b}^{*}$ mode. Colour measurements were conducted before the application of whitening regimens and after 15, 30 and 90 days. Kruskal-Wallis, Mann-Whitney U, Friedman and Wilcoxon Signed Ranks tests for bivariate and post-hoc analysis of $\mathrm{L}^{*}, \mathrm{a}^{*}, \mathrm{~b}^{*}$ parameters and $\Delta \mathrm{E}$ were used.
\end{abstract}

Results: $\mathrm{L}^{*}$ values, in all groups, presented statistically significant higher values while $\mathrm{a}^{*}$ and $\mathrm{b}^{*}$ lower relative to the baseline measurement at 90 days. $10 \% \mathrm{CP}$ agent induced statistically higher $\Delta \mathrm{E}$ values than all self-dispensed products at all intervals.

Conclusions: Although all agents assessed resulted in colour whitening, $10 \% \mathrm{CP}$ was the only one of the products that yielded a clinically perceptible tooth whitening effect $\left(\Delta \mathrm{E}^{*}>2.7\right)$.

\section{Introduction}

Over the past few years an increasing number of tooth whitening products have been developed for vital tooth bleaching. The whitening of teeth is known to be viable using two different approaches. A product can bleach the tooth by actually changing the natural tooth colour. Usually, bleaching products containing peroxide(s) remove deep (intrinsic) and surface (extrinsic) stains thus producing a combined internal and external whitening effect. In contrast, non-bleaching whitening products contain abrasives and agents that induce surface stain removal mainly by mechanical or/and chemical procedures [1]. Vital bleaching systems currently available may be professionally administered (in-office or at-home systems) or self-directed (products directly selected by consumers) [2]. Professionally administrated use of $10 \%$ carbamide peroxide $(\mathrm{CP})$ in a custom-made tray, under various protocols, is a widely acceptable, safe and well-documented efficient at-home tooth whitening method [1,3-8]. On the other hand, the selfdirected systems are low-cost and easily accessible worldwide. These are provided as a modern, popular, economic alternative tooth-whitening approach [2,9]. Many different products including dentifrices, mouth rinses, dental floss, chewing gums, paint-on gels or varnishes and strips are on the market. Dentifrices contain abrasives and various other active chemical agents such as, hydrogen peroxide (HP), calcium peroxide, sodium citrate, sodium pyrophosphate, sodium tripolyphosphate, sodium hexametaphosphate and papain [10]. Mouth rinses, generally, contain HP in a concentration of 1.0-1.5\% and sodium hexametaphosphate for the protection against stain accumulation. Chewing gums, which contain $4.0-7.5 \%$ sodium hexametaphosphate, can also be considered as self-directed whitening products [11]. Painton gels or varnishes are barrier-free peroxide whitening products with either HP or CP [12]. Finally, whitening adhesive strips which bond to the anterior teeth and release HP in low concentrations (5-14\%) [13].

Most of the studies concerning the efficacy of whitening dentifrices have documented their ability to remove only extrinsic stains from tooth surfaces [10,14-16]. Furthermore, studies for barrier-free peroxide varnishes target the comparison of various application protocols, dispensing systems and comparisons among similar products of different composition, as well as with other self-directed categories [2,17-21]. However, there is no evidence of the whitening effect of the dentifrices and varnishes relative to a well-documented whitening agent such as the $10 \% \mathrm{CP}$.

Therefore, the objective of this randomized, controlled, singleblind, four parallel group clinical study was to evaluate the potential for tooth colour whitening derived from self-directed whitening agents - two whitening dentifrices and a peroxide barrier-free varnish - in comparison to the positive control $10 \% \mathrm{CP}$ agent for a period up to 90

Correspondence to: Antoniadou Maria, Operative Dentistry Department, Dental School, National and Kapodistrian, University of Athens, Thivon 2, Goudi, Greece, Tel: 00306944342546; E-mail: mantonia@dent.uoa.gr

Key words: bleaching agent, carbamide peroxide, whitening dentifrices, varnish

Received: February 24, 2015; Accepted: March 28, 2015; Published: April 03, 2015 
days, in young adults. The research hypothesis was that no differences exist between the types of self-directed whitening agents tested and the $10 \% \mathrm{CP}$ as well as among the self-directed products.

\section{Materials and methods}

The Ethics Committee of Athens Dental School approved this randomized, parallel equivalence clinical trial. One hundred and twenty three (123) Caucasian people aged between 20-30 years, studying or working at the Dental School of Athens, Athens, Greece, who expressed interest in tooth whitening were selected for initial screening. All of them had undergone a visually assessed procedure of their teeth before the start of the trial. Candidates were screened by the dental examiner in order to identify those subjects who met the inclusion/exclusion criteria. Inclusion criteria per subject were $[5,19]$ : availability for the duration of the project, six maxillary and mandibular anterior intact teeth, initial minimum baseline shade of A3 on more than one of the upper or lower front teeth that were to be examined in order to allow for broad inference of study results, no current or previous use of bleaching products, good general health (no serious medical disease, no medication) and good oral hygiene (no inflammation or plaque accumulation). The exclusion criteria were: smokers, pregnant or lactating women, previous or current orthodontic treatment, prosthetic or conservative restorations, caries or enamel defects in the anterior upper and lower teeth, intrinsically stained teeth, heavily extrinsic staining due to drinks (tea, coffee, wine etc.), advanced periodontal diseases, poor oral hygiene, history of allergy, participation in another clinical study. Ninety-six (96) subjects were finally accepted for the study. All participants signed a participation and informative consent form that outlined all procedures and defined the alternatives prior to enrolment into the study.

Women $(n=70)$ and men $(n=26)$ were divided into four equally numbered groups. The allocation process was performed by one person, who was not one of the researchers of the current study. Numbers were assigned to patients according to the recruitment date. Determination of the whitening approach per subject of the numbered list was performed by the same person based on the baseline tooth colour score to ensure balance below and above shade tab A3 in the sum of the teeth tested per subject and age since these factors are known to impact clinical response [2]. The same person gave the whitening products to the participants, which were unknown to the two tooth colour examiners.

Each group received a certain product/procedure (Table 1). Group A (Colgate Herbal White, Colgate-Palmolive Co., NY, USA) and B (Propoline, Apivita, Greece) were given the relevant whitening dentifrice; Group C the peroxide barrier-free varnish (Unident Pen, Intermed, Greece) and Group D the 10\% CP (Opalescence 10\%, Ultradent Products Inc., USA) in custom-made trays. All products were administered straight from the manufacturers, stored according to directions of use and given for application within a month from the delivery day. Products A, B and C were relatively and uniformly masked with a white plastic patch so that participants and subsequently, examiners would be unaware of the content.

All participants per group received written instructions for oral hygiene and application procedure. Specifically, participants of groups A and B were instructed to use an amount equal to a pea of the dentifrice given. The teeth should be brushed following the Bass method, for $2 \mathrm{~min}$, twice per day, for 30 days. Participants in group $\mathrm{C}$ applied the varnish twice per day (morning and afternoon), for 15 days. Prior to the use of varnish, excess moisture should have been removed with tissue, gauze or cotton pad. Lips should not be in contact with teeth for at least $30 \mathrm{sec}$ following placement of the material. 15 minutes after application participants should thoroughly rinse their mouth. Participants in group D used custom-made trays, formed out of individual alginate impressions of the upper and lower jaw. The trays had reservoirs spacers in the buccal surface of $0.5 \mathrm{~mm}$ and there was a 0.5-1 mm extension from the free gingival margin. Participants were instructed to use a pea-sized amount of bleaching material for every tooth (\# 15 to 25 and 35 to 45 ) both in the upper and the lower jaw simultaneously. Trays should remain in place for 120 minutes once per day, for 15 days. Participants in $\mathrm{C}$ and $\mathrm{D}$ groups were instructed to use their common dentifrice and also to brush their teeth for $2 \mathrm{~min}$ prior to the bleaching procedure. Application time for $\mathrm{C}$ and $\mathrm{D}$ groups was conducted according to the directions of use of the material. All participants were instructed to use only the products provided during the testing period. A new toothbrush was also given for exclusive use during the recording period (AIM Style Tech, medium, Unilever Co., USA). Avoidance of food/drink consumption for 1 hour after each procedure was recommended. After the test period their natural hygiene habits should be followed without introducing new whitening products into the daily routine and they should not use the remaining material assigned to them. In order to ensure this, participants in $\mathrm{C}$ and $\mathrm{D}$ groups were asked to return packages at 15- and those of $\mathrm{A}$ and $B$ groups at 30-days examination stage.

Anterior teeth 12, 21, 23, 33 and 41 of each patient - a total of 480 teeth-were subjected to colour determination in the middlethird of their facial surface with a digital spectrophotometer device (SpectroShade ${ }^{\mathrm{Tx}}$, MHT Optic Research AG, Switzerland) operated in $L^{\star}, a^{*}, b^{*}$ CIELab, by free-hand and according to the manufacturer's directions of clinical use. Colour recording was performed just before starting procedures $\left(\mathrm{t}_{0}\right)$ and after $15\left(\mathrm{t}_{1}\right), 30\left(\mathrm{t}_{2}\right)$ and $90\left(\mathrm{t}_{3}\right)$ days. Every measurement was taken in the setting of a dental office, by two specialists in operative dentistry and calibrated examiners (calibration score 92\%), three times per examiner at each appointment. The two examiners were unaware of the whitening group of each patient. All

Table 1. The tooth whitening products used in the study.

\begin{tabular}{|l|l|l|l|}
\hline \multicolumn{1}{|c|}{ Product } & \multicolumn{1}{|c|}{ Manufacturer } & \multicolumn{1}{c|}{ Form } & Composition \\
\hline A. Colgate Herbal White & $\begin{array}{l}\text { Colgate-Palmolive Co., } \\
\text { NY, USA }\end{array}$ & Super market's Toothpaste & $\begin{array}{l}\text { Sodium monofluorophosphate, Sodium bicarbonate, Sodium lauryl sulfate, } \\
\text { Calcium carbonate, SilicaEucalyptus }\end{array}$ \\
\hline B. Propoline & Apivita, Greece & Pharmaceutical Toothpaste & $\begin{array}{l}\text { Mastic, Aloe Vera, Bio-active Propolis, Pro-vitamin B5, } \\
\text { Allantoin, Lemon oil, Sodium bicarbonate, } \\
\text { Pentasodium triphosphate, Calcium Glycerophosphate }\end{array}$ \\
\hline C. Unident Pen & Intermed, Greece & $\begin{array}{l}\text { Pharmaceutical } \\
\text { Barrier-free Varnish }\end{array}$ & $\begin{array}{l}3,6 \% \text { Hydrogen Peroxide } \\
\text { Dentist prescribed } \\
\text { in Splints }\end{array}$ \\
\hline D. Opalescence 10\% & $\begin{array}{l}\text { Ultradent Products Inc., } \\
\text { USA }\end{array}$ & & $\begin{array}{l}10 \% \text { Carbamide Peroxide } \\
2,7 \% \text { Sodium hydroxide }\end{array}$ \\
\hline
\end{tabular}

"Manufacturers' data sheet on the packages 
measurements were during the early afternoon (12.00-15.00), under the same light conditions representing a laboratory situation (daylight lamp at $\left.5500^{\circ} \mathrm{K}\right)$. For the tooth colour changes the most extensively used formula is derived from the CIE $\mathrm{L}^{*}, \mathrm{a}^{*}, \mathrm{~b}^{\star}$ system, where $\Delta \mathrm{L}^{*}$, $\Delta \mathrm{a}^{*}$ and $\Delta \mathrm{b}^{*}$ are the differences in lightness-darkness, green-red and blue-yellow coordinates respectively. Colour changes per tooth tested in each individual were calculated as $\Delta \mathrm{E}^{*}=\left[\left(\Delta \mathrm{L}^{*}\right)^{2}+\left(\Delta \mathrm{a}^{*}\right)^{2}+\left(\Delta \mathrm{b}^{*}\right)^{2}\right]^{1 / 2}$ (9) relative to the baseline measurement at $t_{1}, t_{2}$ and $t_{3}$ time points to determine the colour change effect of the agents assessed.

The values of all variables of the study were not normally distributed. Consequently, the Kruskal-Wallis test was used to investigate the impact of each whitening treatment on $\mathrm{L}^{\star}, \mathrm{a}^{\star}, \mathrm{b}^{*}$ and $\Delta \mathrm{E}$ values versus time assessment. Additionally, post-hoc analysis with the use of Mann-Whitney $U$ test was applied for the evaluation of the differences in mean values of the above parameters in the different groups of the study. The Friedman test was also used for comparison between the repeated $\Delta \mathrm{E}$ measures. In addition, post-hoc analysis with the use of Wilcoxon Signed Ranks test was performed for assessing the mean differences between time points. All reported probability values (p-values) were compared to a significant level of 5\%. The analyses of coded data were carried out using IBM SPSS software version 21.0.

\section{Results}

The overall drop-out of the participants was 0 at $t_{1}, 3.1 \%$ at $t_{2}$ $(\mathrm{n}=3)$ and $46.8 \%$ at $\mathrm{t}_{3}(\mathrm{n}=45)$ recalls. At $\mathrm{t}_{2}$, drop-out percentages were distributed as $0 \%, 8.3 \%(\mathrm{n}=2), 4.1 \%(\mathrm{n}=1)$ and $0 \%$ for $\mathrm{A}, \mathrm{B}, \mathrm{C}$, $\mathrm{D}$ groups, accordingly. The corresponding drop-out values at $\mathrm{t}_{3}$ were 45.8\% $(n=11), 50.0 \%(n=12), 50.0 \%(n=12)$ and $41.7 \%(n=10)$ for A, B, $\mathrm{C}, \mathrm{D}$ groups, respectively. Further, the sample size was considered as adequate because achieved or post hoc statistical power was computed at least 0.83 for all colour parameters (minimum effect size was found 0.77, using Cohen's d as measure of effect size, at 5\% alpha level).

Mean values and statistical differences per group for the $L^{*}, a^{*}, b^{*}$ colour parameters at all time-intervals are shown in Table $2 . \mathrm{L}^{*}$ values, in all groups, at the 90 -days recall were significantly higher while $\mathrm{a}^{*}$ and $\mathrm{b}^{*}$ were lower relative to the baseline $\left(\mathrm{t}_{0}\right)$ measurements.

Mean values for $\Delta \mathrm{E}$ parameter for the whitening groups at all time-intervals are presented in Table 3 . The $10 \% \mathrm{CP}$ agent (group D) induced statistically higher $\Delta \mathrm{E}$ values than the self-directed products during all follow-up times. Colgate Herbal White (group A) caused statistically higher $\Delta \mathrm{E}$ values than Propoline (group B) and Unident Pen (group C) at 30 and 90 -days recalls. No statistically significant differences in terms of $\Delta \mathrm{E}$ values were detected between Propoline (group B) and Unident Pen (group C) treatments at any time interval. $\Delta \mathrm{E}$ values were statistically increased at 30 and 90 days compared to 15 days in all groups and between 30 to 90 days only between the two whitening dentifrices $(\mathrm{A}, \mathrm{B})$.

\section{Discussion}

Most of the clinical studies evaluate the efficacy of tooth-whitening agents using dental shade guides. This method is a highly subjective one [12] and variables such as observer's experience, eye fatigue, ambient light conditions, and the background against which a tooth is compared may lead to inconsistencies [22]. To overcome these problems, spectrophotometric assessment of tooth shade was recommended $[14,23,24]$ and so it was selected as a colour measurement approach in the current study.

Furthermore, it was suggested that the determination of $\Delta \mathrm{E}^{\star}$ $[9,25]$ is of little clinical value unless an acceptability (AT) (the colour difference that is clinically acceptable) and a perceptibility (PT) (the difference that is perceivable to an observer) threshold are identified [26]. So far, there is a consensus that the determination of $\Delta E^{*}$ is appropriate to define AT and PT, however, there is no consensus regarding the values that should be used. It was recently reported [25] that $\Delta \mathrm{E}^{*}$ value of 1 is visually detectable $50 \%$ of the time (PT) with the majority of studies referring to Kuehni and Marcus [27], Seghi et al. [28] and Ruyter et al. [29]. As for the acceptability threshold its value ranges between 2.0 and 4.0 where as much as one third of the literature refers to its value as being 3.7 based on suggestions made by Johnston and Kao, in 1989 [30]. However, according to the results obtained from a recent clinical study investigating natural tooth colour, 2.7 units can be determined as the PT threshold [31].

In this randomized, single-blind positive-controlled clinical trial the research hypothesis that two types of self-directed products have the same potential for tooth whitening as $10 \% \mathrm{CP}$ up to 90 days posttreatment time, was rejected since all self-directed products generated a milder tooth whitening result compared to $10 \% \mathrm{CP}$. In addition, differences among the self-directed products were assessed. More specifically, dentifrice Colgate Herbal White (Colgate-Palmolive Co., NY USA), 90 days after starting the procedure, manifested a stronger whitening effect than the other dentifrice (Propoline, Apivita, Greece) and the peroxide barrier-free varnish (Unident Pen, Intermed, Greece), whereas Propoline and Unident Pen exhibited a similar performance.

$10 \% \mathrm{CP}$ was the only product of the present study contributing to perceptible outcomes $\left(\Delta \mathrm{E}^{*}>2.7\right)$. The colour change obtained by $10 \% \mathrm{CP}$ is documented in clinical studies although diversities can be

Table 2. Mean values (first line) and \pm standard deviations (second line) of the $\mathrm{L}^{*}, \mathrm{a}^{*}, \mathrm{~b}^{*}$ parameters for the whitening methods tested (Groups A and B: whitening dentifrices, Group C: varnish, Group D: $10 \%$ Carbamide Peroxide) at all time intervals $\left(\mathrm{t}_{0}:\right.$ baseline, $\mathrm{t}_{1}: 15$ days, $\mathrm{t}_{2}: 30$ days, $\mathrm{t}_{1}: 90$ days)."

\begin{tabular}{|c|c|c|c|c|c|c|c|c|c|c|c|c|}
\hline \multirow[b]{2}{*}{ Whitening methods } & \multicolumn{4}{|c|}{$\mathbf{L}^{*}$} & \multicolumn{4}{|c|}{$\mathbf{a}^{*}$} & \multicolumn{4}{|c|}{$\mathbf{b}^{*}$} \\
\hline & $\mathbf{t}_{\mathbf{0}}$ & $t_{1}$ & $t_{2}$ & $t_{3}$ & $t_{0}$ & $t_{1}$ & $\mathbf{t}_{2}$ & $\mathbf{t}_{3}$ & $\mathbf{t}_{0}$ & $t_{1}$ & $\mathbf{t}_{2}$ & $\mathbf{t}_{3}$ \\
\hline \multirow[t]{2}{*}{ Group A } & $57.65^{1}$ & $62.41^{2}$ & $62.61^{3}$ & $62.23^{4}$ & $4.43^{1}$ & $4.36^{1}$ & $4.28^{2}$ & $4.27^{3}$ & $10.03^{1}$ & $9.86^{1}$ & $9.67^{2}$ & $9.48^{3}$ \\
\hline & $( \pm 2.19)$ & $( \pm 4.58)$ & $( \pm 4.70)$ & $( \pm 4.67)$ & $( \pm 1.05)$ & $( \pm 0.95)$ & $( \pm 0.94)$ & $( \pm 0.94)$ & $( \pm 2.60)$ & $( \pm 2.53)$ & $( \pm 2.39)$ & $( \pm 2.36)$ \\
\hline \multirow[t]{2}{*}{ Group B } & $56.33^{1}$ & $56.59^{2}$ & $56.91^{3}$ & $56.80^{2}$ & $4.57^{1}$ & $4.47^{2}$ & $4.42^{3}$ & $4.35^{4}$ & $10.42^{1}$ & $10.15^{2}$ & $10.14^{2,3}$ & $10.07^{2,4}$ \\
\hline & $( \pm 4.93)$ & $( \pm 4.91)$ & $( \pm 4.76)$ & $( \pm 4.53)$ & $( \pm 0.94)$ & $( \pm 0.92)$ & $( \pm 0.84)$ & $( \pm 0.83)$ & $( \pm 2.43)$ & \pm 2.38 & $( \pm 2.24)$ & $( \pm 2.26)$ \\
\hline \multirow[t]{2}{*}{ Group C } & $56.28^{1}$ & $56.82^{2}$ & $57.28^{3}$ & $57.09^{3}$ & $4.79^{1}$ & $4.58^{2}$ & $4.58^{3}$ & $4.51^{4}$ & $10.68^{1}$ & $10.25^{2}$ & $10.21^{3}$ & $10.10^{4}$ \\
\hline & $( \pm 3.57)$ & $( \pm 3.59)$ & $( \pm 2.89)$ & $( \pm 3.40)$ & $( \pm 1.03)$ & $( \pm 1.02)$ & $( \pm 1.00)$ & $( \pm 1.00)$ & $( \pm 2.39)$ & \pm 2.39 & $( \pm 2.24)$ & $( \pm 2.21)$ \\
\hline \multirow[t]{2}{*}{ Group D } & $55.87^{1}$ & $58.06^{2}$ & $58.45^{3}$ & $57.93^{2}$ & $4.83^{1}$ & $4.06^{2}$ & $4.08^{2}$ & $4.00^{3}$ & $10.66^{1}$ & $8.71^{2}$ & $8.80^{2,3}$ & $8.58^{2,4}$ \\
\hline & $( \pm 4.07)$ & $( \pm 2.28)$ & $( \pm 2.19)$ & $( \pm 2.00)$ & $( \pm 1.08)$ & $( \pm 0.81)$ & $( \pm 0.77)$ & $( \pm 0.73)$ & $( \pm 2.27)$ & $( \pm 2.08)$ & $( \pm 1.94)$ & $( \pm 1.85)$ \\
\hline
\end{tabular}

Different numbers within the rows for each parameter $\left(\mathrm{L}^{*}, \mathrm{a}^{*}, \mathrm{~b}^{*}\right)$ indicate statistically significant differences between time points for each group, Friedman test and post-hoc Wilcoxon Signed Ranks test, $\mathrm{p}<0.05$. 
Table 3. Mean values and \pm standard deviations of the $\Delta \mathrm{E}$ parameter (calculated relative to baseline) for the whitening methods tested (Groups A and B: whitening dentifrices, Group C: varnish, Group D: $10 \%$ Carbamide Peroxide) at all time intervals $\left(\mathrm{t}_{0}:\right.$ baseline, $\mathrm{t}_{1}: 15$ days, $\mathrm{t}_{2}: 30$ days, $\mathrm{t}_{1}: 90$ days).*

\begin{tabular}{|l|c|c|c|}
\hline \multicolumn{5}{|c|}{$\Delta \mathbf{E}$} \\
\hline Whitening methods & $\mathbf{t}_{\mathbf{1}}$ & $\mathbf{t}_{\mathbf{2}}$ & $\mathbf{t}_{\mathbf{3}}$ \\
\hline Group A & $1.83( \pm 2.02)^{\mathrm{a}, 1}$ & $2.17( \pm 1.77)^{\mathrm{a}, 2}$ & $2.39( \pm 1.99)^{\mathrm{a}, 3}$ \\
\hline Group B & $1.36( \pm 1.74)^{\mathrm{a}, 1}$ & $1.58( \pm 1.56)^{\mathrm{b}, 2}$ & $1.92( \pm 1.97)^{\mathrm{b}, 3}$ \\
\hline Group C & $1.39( \pm 2.38)^{\mathrm{a}, 1}$ & $1.69( \pm 2.32)^{\mathrm{b}, 2}$ & $1.77( \pm 2.29)^{\mathrm{b}, 2}$ \\
\hline Group D & $3.19( \pm 2.28)^{\mathrm{b}, 1}$ & $3.45( \pm 2.32)^{\mathrm{c}, 2}$ & $3.73( \pm 2.17)^{\mathrm{c}, 2}$ \\
\hline
\end{tabular}

"Different letters within the columns indicate statistically significant differences among the Groups (A, B, C, D) for each time point/ $\left(\mathrm{t}_{1}, \mathrm{t}_{2}, \mathrm{t}_{3}\right)$, Mann-Whitney $\mathrm{U}$ test, $\mathrm{p}<0.05$.

Different numbers within the rows indicate statistically significant differences between time points for each group, Friedman test and post-hoc Wilcoxon Signed Ranks test, $\mathrm{p}<0.05$.

verified among studies concerning the $\Delta \mathrm{E}^{\star}$ values recorded [5,32-35]. After application of $10 \%$ CP, 2 hours/day for 3 weeks, on teeth shaded as $\mathrm{C} 1$ or darker, $\Delta \mathrm{E}^{*}$ values of $4.1,3.8$ and 4.3 were measured at one week, six months and one year assessments, accordingly $[5,32,33]$. Even higher whitening effects were provided by Opalescence $10 \%$ that was applied to teeth darker than A2 for 14 days, at least for 4 hours daily [34]. In the present study, the mean $\Delta \mathrm{E}^{\star}$ value reached 3.73 at 90-day recall. Although several approaches in procedures followed can cause differences in $\Delta \mathrm{E}^{\star}$ values, it is notable that, in most of the clinical studies, CP generates $\Delta \mathrm{E}^{\star}$ values above the threshold of 2.7. [22,25,35]. In addition, the findings of the current study support the maintenance and improvement of the $10 \% \mathrm{CP}$ bleaching effect within the 90-day post-treatment time. Meireles et al. [5] reported a maintenance period of six months, suggesting that part of the bleaching process with peroxides continues after the end of the active bleaching phase. The latter may imply that the oxidation-reduction reaction takes place even after cessation of the application of bleaching products [33].

Concerning the efficacy of self-directed products, controversial results have been reported so far. Visually observable colour change was not achieved after application of a dentifrice $1 \% \mathrm{HP}$ and a paint-on gel 18\% CP for 14 days [20]. These findings are, however, opposed to data stated by Neiderman et al. [36]. Whiteness of up to two shade guide units, even with placebo products, has been documented in almost $20 \%$ of the subjects. Furthermore, a $\Delta \mathrm{E}^{\star}$ value of 4.1 was achieved after self-directed use of products for 15 days [37]. The variety of products assigned, along with the different application procedures followed and the colour measurement methods used, do not allow accurate and reliable comparison among these relevant studies.

It has been documented that the whitening dentifrices remove and/or prevent extrinsic tooth stains more effectively than the nonwhitening analogues possibly due to the incorporated abrasive components [10]. Both dentifrices evaluated in the present study are formulated only by abrasives. Therefore, it is expected that they succeed in the removal of extrinsic stains rather than intrinsic colour alterations of the natural tooth shade. In this respect, both dentifrices exhibited a whitening effect which was, however, below the perception of the human eye threshold $\left(\Delta \mathrm{E}^{*}<2.7\right)$. Furthermore, it is known that ccontributing factors for the whitening potential of the dentifrices are the type, particle size, shape, combination and concentration of the abrasives [9-11]. Since considerable differences in the composition of abrasives exist between the two dentifrices used in the study (Table 1), their significant different whitening performance is reported as reasonable.

The chemical agent $3.6 \% \mathrm{HP}$ as a component of the peroxide varnish (Unident Pen) induced less whitening effect than the $10 \% \mathrm{CP}$ (Opalescence $10 \%)$ and was also not perceptible $\left(\Delta \mathrm{E}^{\star}<2.7\right)$. This may be attributed to its barrier-free application form which may increase the possibility of premature peroxide removal by lip or tongue and consequently lead to reduction of the contact time with the enamel surface [40]. Furthermore, less application time per day of the varnish relative to the $10 \% \mathrm{CP}$ may contribute to the milder whitening results achieved. Concerning varnishes and gels, it has been generally suggested that factors such as frequency, time and mode of application may contribute to their whitening ability [20]. It is notable though that the peroxide varnish did not manifest a stronger whitening effect compared to the two dentifrices, which are peroxide-free. This can possibly be attributed to the less time that the varnish actually stays on the tooth surfaces than what is suggested by the manufacturer. A matter for further research should be the possibility that abrasives may be more efficient than peroxides when incorporated into the synthesis of whitening materials that generally perform below the perceivable $\Delta \mathrm{E}^{\star}$ threshold.

$\Delta \mathrm{E}^{*}$ values observed at all time points for all self-directed products of the current study indicate a continuous whitening effect. It remains as a cause of concern as to whether the tooth whitening progress was continued up to the last follow-up visit although the whitening processes were completed within the first 15 or 30 days. The adherence of the participants returned to the recall oral examination to better oral hygiene habits may account for this fact [41]. The relevant literature further stresses the better oral hygiene habits achieved after whitening procedures [2].

Generally, the use of whitening intensives leads to measurable differences in all three colour parameters, specifically increased lightness $\left(+\Delta \mathrm{L}^{\star}\right)$, decreased redness $\left(-\Delta \mathrm{a}^{\star}\right)$ and decreased yellowness $\left(-\Delta b^{*}\right)[2,5,32]$. In cases of sufficient improvement $(-b$ and $+\mathrm{L})$ the colour change is considered as "whitening" $[2,20]$. This trend is also obvious in the current study for all groups, when the baseline values for colour parameters are compared with the corresponding ones recorded after 90 days. The latter phenomenon further suggests that no relapse phenomenon has taken place, as was the case reported elsewhere [3].

This study specifically targeted a university-aged population (20-30 years old) as this age group is supposed to be aware of tooth discolouration and interested in aesthetic smile interventions $[42,43]$. Despite this fact the overall drop-out percentage at 90 days is considered critical $(46,8 \%)$. It should be noted that certain precautions should be taken in future research in order to guarantee recall appointments. Also additional research would be needed to compare other instrumental or digital image analysis methods in order to avoid bias provided by lighting or limitations of the instrument the assessment of slight colour changes.

\section{Conclusions}

- $10 \%$ carbamide peroxide achieved a stronger whitening effect than the self-directed dentifrices and the peroxide varnish evaluated.

- A statistically significant difference in terms of whitening efficacy was detected between the two dentifrices.

- The peroxide varnish resulted in a lower degree of whitening in comparison to one of the dentifrices.

- $10 \%$ carbamide peroxide was the only one of the products tested that yielded a clinically perceptible tooth whitening effect $\left(\Delta \mathrm{E}^{\star}>2.7\right)$. 


\section{References}

1. ADA. Statement on the safety and effectiveness of tooth whitening products

2. Gerlach RW, Zhou X (2001) Vital bleaching with whitening strips: summary of clinica research on effectiveness and tolerability. J Contemp Dent Pract 2: 1-16. [Crossref]

3. Zekonis R, Matis BA, Cochran MA, Al Shetri SE, Eckert GJ, et al. (2003) Clinical evaluation of in-office and at-home bleaching treatments. Oper Dent 28: 114-121. [Crossref]

4. Brunton PA, Ellwood R, Davies R (2004) A six-month study of two self-applied tooth whitening products containing carbamide peroxide. Oper Dent 29: 623-626. [Crossref]

5. Meireles SS, Heccmann SS, Leida FL, Santos IS, Bella Bona A, Demarco F (2008a) A double blind randomized clinical trial of at-home tooth bleaching using two carbamide peroxide concentrations: 6-month follow up. J Dent 36(11): 878-884.

6. Haywood VB (1997) Nightguard vital bleaching: current concepts and research. J Am Dent Assoc 128 Suppl: 19S-25S. [Crossref]

7. Matis BA, Mousa HN, Cochran MA, Eckert GJ (2000) Clinical evaluation of bleaching agents of different concentrations. Quintessence Int 31: 303-310. [Crossref]

8. Auschill TM, Hellwig E, Schmidale S, Sculean A, Arweiler NB (2005) Efficacy, sideeffects and patients' acceptance of different bleaching techniques (OTC, in-office, athome). Oper Dent 30: 156-163. [Crossref]

9. Gerlach RW, Barker ML (2003) Clinical response of three direct-to-consumer whitening products: strips, paint-on gel, and dentifrice. Compend Contin Educ Dent 24: 458, 461-464, 466 passim. [Crossref]

10. Lima DA, Silva AL, Aguiar FH, Liporoni PC, Munin E, et al. (2008) In vitro assessment of the effectiveness of whitening dentifrices for the removal of extrinsic tooth stains. Braz Oral Res 22: 106-111. [Crossref]

11. Demarco FF, Meireles SS, Masotti AS (2009) Over-the-counter whitening agents: a concise review. Braz Oral Res 23 Suppl 1: 64-70. [Crossref]

12. Kishta-Derani M, Neiva G, Yaman P, Dennison J (2007) In vitro evaluation of toothcolor change using four paint-on tooth whiteners. Oper Dent 32: 394-398. [Crossref]

13. Donly KJ, Henson T, Jamison D, Gerlach RW (2006) Clinical trial evaluating two peroxide whitening strips used by teenagers. Gen Dent 54 : 110-112. [Crossref]

14. Walsh TF, Rawlinson A, Wildgoose D, Marlow I, Haywood J, et al. (2005) Clinical evaluation of the stain removing ability of a whitening dentifrice and stain controlling system. J Dent 33: 413-418. [Crossref]

15. Terezhalmy GT, Biesbrock AR, Farrell S, Barker ML, Bartizek RD (2007) Tooth whitening through the removal of extrinsic stain with two sodium hexametaphosphatecontaining whitening dentifrices. Am J Dent 20(5): 309-314

16. Hugues N, Maggio B, Sufi F, Mason S, Kleber CJ (2009) A comparative clinical study evaluating stain removal efficacy of a new sensitivity whitening dentifrice compared to commercially available whitening dentifrices. J Clin Dent 20(7): 218-222.

17. Barlow A, Gerlach RW, Date RF, Brennan K, Struzycka I, et al. (2003) Clinical response of two brush-applied peroxide whitening systems. J Clin Dent 14: 59-63. [Crossref]

18. Collins LZ, Maggio B, Liebman J, Blanck M, Lefort S, et al. (2004) Clinical evaluation of a novel whitening gel, containing $6 \%$ hydrogen peroxide and a standard fluoride toothpaste. J Dent 32 Supp1 1: 13-17. [Crossref]

19. Li Y, Lee SS, Cartwright S, Wilson AC, DeVizio W, et al. (2004) Comparative tooth whitening efficacy of $18 \%$ carbamide peroxide liquid whitening gel using three different regimens. J Clin Dent 15: 11-16. [Crossref]

20. Gerlach RW, Barker ML, Tucker HL (2004) Clinical response of three whitening products having different peroxide delivery - comparison of tray paint-on-gel and dentifrice. J Clin Dent 15(4): 112-117.

21. Xu X, Zhu L, Tang Y, Wang Y, Zhang K, et al. (2007) Randomized clinical trial comparing whitening strips, paint-on gel and negative control. Am J Dent $20 \mathrm{Spec}$ No A: 28A-31A. [Crossref]

22. Ishikawa-Nagai S, Terui T, Ishibashi K, Weber HP, Ferguson M (2004) Prediction of optical efficacy of vital tooth bleaching using regression analysis. Color Res Applic 29: 390-394.
23. Okubo SR, Kanawati A, Richards MW, Childress S (1998) Evaluation of visual and instrument shade matching. J Prosthet Dent 80: 642-648. [Crossref]

24. Derdilopoulou FV, Zantner C, Neumann K, Kielbassa AM (2007) Evaluation of visua and spectrophotometric shade analyses: a clinical comparison of 3758 teeth. Int $J$ Prosthodont 20: 414-416. [Crossref]

25. Khashayar G, Bain PA2, Salari S3, Dozic A4, Kleverlaan CJ4, et al. (2014) Perceptibility and acceptability thresholds for colour differences in dentistry. $J$ Dent 42: 637-644. [Crossref]

26. Douglas RD, Steinhauer TJ, Wee AG (2007) Intraoral determination of the tolerance of dentists for perceptibility and acceptability of shade mismatch. J Prosthet Dent 97 200-208. [Crossref]

27. Kuehni RG, Marcus RT (1979) An experiment in visual scaling of small colour differences. Colour Res Applic 4: 83-91.

28. Seghi RR, Hewlett ER, Kim J (1989) Visual and instrumental colorimetric assessments of small color differences on translucent dental porcelain. J Dent Res 68: 1760-1764. [Crossref]

29. Ruyter IE, Nilner K, Moller B (1987) Color stability of dental composite resin materials for crown and bridge veneers. Dent Mater 3: 246-251. [Crossref]

30. Johnston WM, Kao EC (1989) Assessment of appearance match by visual observation and clinical colorimetry. J Dent Res 68: 819-822. [Crossref]

31. Da Silva JD, Park SE, Weber HP, Ishikawa-Nagai S (2008) Clinical performance of a newly developed spectrophotometric system on tooth color reproduction. J Prosthet Dent 99: 361-368. [Crossref]

32. Meireles SS, Heckmann SS, Leida FL, dos Santos Ida S, Della Bona A, et al. (2008) Efficacy and safety of $10 \%$ and $16 \%$ carbamide peroxide tooth-whitening gels: a randomized clinical trial. Oper Dent 33: 606-612. [Crossref]

33. Meireles SS, Da Silva Dos Santos I, Della Bona A, Demarco FF (2009) A double-blind randomized controlled clinical trial of 10 percent versus 16 percent carbamide peroxide tooth bleaching agents. J Am Dent Assoc 140: 1109-1117.

34. Grobler SR, Majeed A, Hayward R, Rossouw RJ, Moola MH, et al. (2011) A clinica study of the effectiveness of two different $10 \%$ carbamide peroxide bleaching products a 6-month followup. Int J Dent 2011: 167525. [Crossref]

35. Bizhang M, Chun YH, Damerau K, Singh P, Raab WH, et al. (2009) Comparative clinical study of the effectiveness of three different bleaching methods. Oper Dent 34 635-641. [Crossref]

36. Niederman R, Tantraphol MC, Slinin P, Hayes C, Conway S (2000) Effectiveness of dentist-prescribed, home-applied tooth whitening. A meta analysis. J Contemp Dent Pract 1: 20-36. [Crossref]

37. Matis BA, Cochran MA, Eckert GJ, Matis JI (2007) In vivo study of two carbamide peroxide gels with different desensitizing agents. Oper Dent 32: 549-555. [Crossref]

38. Wülknitz P (1997) Cleaning power and abrasivity of European toothpastes. Adv Dent Res 11: 576-579. [Crossref]

39. Kleber CJ, Moore MH, Nelson BJ (1998) Laboratory assessment of tooth whitening by sodium bicarbonate dentifrices. J Clin Dent 9: 72-75. [Crossref]

40. Oteo Calatayud J, Mateos de la Varga P, Oteo Calatayud C, Calvo Box MJ (2009) Comparative clinical study of two tooth bleaching protocols with $6 \%$ hydrogen peroxide. Int J Dent 2009: 928306. [Crossref]

41. Worschech CC, Rodriguez JA, Martins LR, Ambrosano GM (2003) In vitro evaluation of human dental enamel surface roughness bleached with $35 \%$ carbamide peroxide and submitted to abrasive dentifrice brushing. Braz Oral Res 17: 342-348.

42. Odioso LL, Gibb RD, Gerlach RW (2000) Impact of demographic, behavioral, and dental care utilization parameters on tooth color and personal satisfaction. Compend Contin Educ Dent Suppl : S35-41. [Crossref]

43. Guerrero JC, Jiménez-Farfán MD, Lopez-Salgado A, Barker ML, Gerlach RW (2007) Professional whitening strips in a university population. Am J Dent $20 \mathrm{Spec}$ No A 15A-18A. [Crossref]

Copyright: (C2015 Antoniadou M. This is an open-access article distributed under the terms of the Creative Commons Attribution License, which permits unrestricted use, distribution, and reproduction in any medium, provided the original author and source are credited. 